thượng nhĩ phần lớn là tái tạo, chỉ có một chỗ khuyết ra nhỏ, thể hiện có túi có kéo và xương con bị ăn mòn. Với tình trạng đó nghi ngờ biến chứng VTTMB do VTG mạn có cholesteatoma là hợp lý. Do tĩnh mạch bên liên quan chặt chẽ với màng tiểu não và tiểu não, khi bệnh nhần có dấu hiệu tổn thương tĩnh mạch bên kèm đau đầu, chụp cộng hưởng từ là cần thiết để khẳng định cholesteatoma, đánh giá tình trạng VTTMB và loại trừ áp xe tiểu não.

Về điều trị, đối với VTTMB trong trường hợp này, sau khi đánh giá tình trạng VTTMB với nhiếm trùng huyết của bệnh nhân, đồng thời khảo sát tình trạng tĩnh mạch cảnh đối bên, chỉ định thắt tĩnh mạch cảnh trong đã được đề ra để tránh huyết khối tiếp tục di cư, chỉ định phẫu thuật hợp lý đồng thời tiến hành phẫu thuật xương chữm kiểm soát tốt cholesteatome, với sử dụng tiêm truyền kháng sinh liều cao phổ rộng. Sau mổ, bệnh nhân phục hồi nhanh chóng, hết sốt và không có bất kỳ dấu hiệu nào biểu hiện của ảnh hưởng toàn trạng sau thắt tĩnh mạch cảnh trong.

\section{KẾT LUẬN}

Ngày nay, biểu hiện lâm sàng của VTG mạn tính có cholesteatoma có nhiều thay đổi, cholesteatoma do thủng màng căng rộng sát xương hiếm gặp mà phần lớn là cholesteatoma xuất phát từ túi co kéo hay cholesteatoma bẩm sinh. Trong VTG mạn có hay không có cholesteatoma, các bệnh tích trong tai cũng rất đa dạng, có chỗ hủy xương, có chỗ tạo xương và vôi hóa. Cholesteatoma có thể biểu hiện dưới dạng màng tai đóng kín, trong đợt hồi viêm dễ nhầm với VTG cấp và khi đó khó phân biệt cholesatome bẩm sinh hay mắc phải. Chính vì vậy, việc hỏi bệnh, thăm khám tỉ mỉ kết hợp với chẩn đoán hình ảnh để phát hiện sớm và điều trị kịp thời là cần thiết, tránh những biến chứng đáng tiếc có thể xảy ra.

\section{TÀI LIẸU THAM KHẢO}

1. Au JK, Adam SI, Michaelides EM. Contemporary management of pediatric lateral sinus thrombosis: a twenty year review. Am J Otolaryngol. 2013; 34: 145150. Ref.: https://goo.gl/TUPPjj.

2. Aquino JE, Cruz Filho NA, de Aquino JN. Epidermiology of middle ear and mastoide cholesteatoma: study of 1146 cases. Braz J Otorhinolaryngolol. 2011; 77 :341-7.

3. Shohet JA, De Jong AI. The management of pediatric cholesteatoma. Otolaryngol Clin N Am. 2002; 35: 841-51.

4. Matthew Yung, Tetsuya Tono, Ewa Olszewska, Yutaka Yamamoto, Holger Sudhoff, Masafumi Sakagami, Jef Mulder, Hiromi Kojima, Armağan İncesulu, Franco Trabalzini, Nuri Özgirgin. EAONO/JOS Joint Consensus Statements on the Definitions, Classification and Staging of Middle Ear Cholesteatoma. J Int Adv Otol 2017; 13: 1-8.

5. Holzmann D, Huisman TAGM, Linder TE. Lateral dural sinus thrombosis in childhood. Laryngoscope 1999;109: 64551.

6. Amirmajdi NM. Sigmoid sinus involvement in middle-ear infection. Laryngoscope 1988; 98: 3102.

7. Agarwal A, Lowry $P$, Isaacson G. Natural history of sigmoid sinus thrombosis. Ann Otol Rhinol Laryngol 2003;112: 191.

8. N. de O. Penido, J.R.G. Testa, D.P.Inoue \& O.L.M, Cruz .Presentation, treatment, and clinical course of otogenic lateral sinus thrombosis. Acta Oto-Laryngologica, 2009; 129: 729734.

9. Manolidis S, Kutz J.W Jr. Diagnosis and management of lateral sinus thrombosis. Otol. Neurotol 2005; 26: 1045-51.

\title{
ĐÁNH GIÁ KẾT QUẢ HOẠT ĐộNG TRI LIỆU TRONG PHỤC HỒI CHỨC NĂNG SINH HOẠT HÀNG NGÀY Ở BỆNH NHÂN NHỒI MÁU NÃO TRÊN LỀU
}

\section{TÓM TẮT}

Đặt vấn đề: Đột quy não để lại nhiều di chứng nặng nề, trong đó sự giảm hoặc mất chức năng sinh hoạt hàng ngày là bước trở ngại đâuu tiên trong việc người bệnh hòa nhập cộng đồng. Mục tiêu: cải thiện

\footnotetext{
*Trường Đại học Y Dước Thái Nguyên

**Trường Đai hoc Y Hà Nôi

Chịu trách nhiệm chính: Nguyễn Thị Thanh Thư

Email: nguyenthanhthu244@gmail.com

Ngày nhận bài: 23.6.2021

Ngày phản biện khoa học: 20.8.2021

Ngày duyệt bài: 27.8.2021
}

\section{Nguyễn Thị Thanh Thư*, Nguyễn Thị Kim Liên**}

sự độc lập trong sinh hoạt hàng ngày. Đối tượng và phướng pháp: Gồm 30 bệnh nhân (BN) đột qự. nhồi máu não trên lều tại Trung tâm Phục hồi chức năng bệnh viện Bạch Mai teo chương trình hoạt động trị liệu vế sinh hoạt hàng ngày. Kết quả: Tuổi trung bình $65,77 \pm 10,15$. Điểm Barthel trung bình trước điêu trị $29,17 \pm 8,62$, điểm Barthel trung bình sau điều trị 1 tháng $62,83 \pm 13,18$, tăng 33,67 điểm. Về mức độ độc lập trong sinh hoạt hàng ngày: Khi vào viện, trong sinh hoạt hàng ngày có tỉ lệ bệnh nhân cân trợ giúp trung bình $80 \%$, phụ thuộc hoàn toàn $20 \%$, 0 bệnh nhân nào thuộc nhóm trợ giúp ít và độc lập hoàn toàn. Sau 1 tháng, 0 bệnh nhân phụ thuộc hoàn toàn, trợ giúp trung bình $36,7 \%$, trợ giúp ít $60 \%$ và độc lập 
hoàn toàn 3,3\%. Cụ thể trong các hoạt động sinh hoạt hàng ngày: Mức độ độc lập hoạt động ăn, tắm, vệ sinh đâu mặt, mặc quẩn áo dịch chuyển, di chuyển, lên xuống cầu thang lúc vào viên lần lướt là $23,3 \%$, $0 \%, 23,3 \%, 0 \%, 0 \%, 0 \%, 0 \%$ sau 1 tháng can thiệp tỷ lệ độc lập trong hoạt động trên lần lượt là $70 \%$, $13,3 \%, 86,7 \%, 13,3 \%, 3,3 \%, 6,7 \%, 3,3 \%$. Kết luận: Phần lớn bênh nhân có cải thiên về điểm Barthel và mức độ độc lập trong sinh hoạt hàng ngày.

Tư khóa: hoạt động trị liệu, phục hồi chức năng, sinh hoạt hàng ngày.

\section{SUMMARY}

\section{THE RESULTS OF OCCUPATIONAL THERAPY IN} THE ACTIVITIES OF DAILY LIVING FOR CEREBRAL INFARCTION ON TENT PATIENTS

Background: A stroke leaves many serious sequelae, in which the reduction or loss of daily living function is the first obstacle in the patient's integration into the community. Objectives: improve independence in daily living. Objects and research methods: Including 30 patients with ischemic stroke on tents at the Rehabilitation Center of Bach Mai hospital with a program of therapeutic activities on daily living. Results: Mean age $65.77 \pm 10.15$. The average Barthel score before treatment was $29.17 \pm$ 8.62 , the average Barthel score after 1 month of treatment was $62.83 \pm 13.18$, an increase of 33.67 points. About the degree of independence in daily life: When admitted to the hospital, in daily activities, the average rate of patients in need of assistance was $80 \%$, completely dependent $20 \%$, 0 patients were in the group with little help and completely independent. After 1 month, 0 patients were completely dependent, average help $36.7 \%$, little help $60 \%$ and completely independent $3.3 \%$. Specifically in daily activities: The degree of independence in eating, bathing, facial hygiene, dressing, moving, moving, going up and down stairs at hospital admission was $23.3 \%$, respectively. $0 \%, 23.3 \%, 0 \%, 0 \%, 0 \%, 0 \%$ after 1 month of intervention, the independent rates in the above activities were $70 \%, 13.3 \%, 86.7 \%, 13$, respectively. $3 \%, 3.3 \%, 6.7 \%, 3.3 \%$. Conclusion: The majority of patients improved in Barthel score and independence in daily activities.

Keywords: Occupational therapy, rehabilitation, activities of daily living.

\section{I. ĐĂT VẤN ĐỀ}

Đột quy não là bệnh phổ biến trên thế giới, là vấn đề lớn của y học, đứng hàng thứ ba sau ung thư và các bệnh tim mạch. Đột quy não là nguyên nhân quan trọng gây nhiều di chứng tàn phế cho người bệnh. Có gần $1 / 3$ đến $2 / 3$ người bênh sống sót sau tai biến, mang di chứng vĩnh viễn [5]. Sau đột quy não người bệnh có thể độc lập chức năng vận động nhưng chưa hẳn độc lập trong các hoạt động sinh hoạt hàng ngày nểu như không được tập luyện. Vì vậy phục hồi chức năng sinh hoạt hàng ngày là một trong những mục tiêu cơ bản và quan trọng giúp người bệnh có thể hội nhập và tái hội nhập xã hội. Theo Burn và cộng sự chứng minh rằng gần $70 \%$ bệnh nhân có thể tự mình thực hiện các kỹ năng và các hoạt động hàng ngày nếu được hướng dẫn phuc hồi [6]. Vì vây chúng tôi thực hiện đề tài: "Đánh giá kêt quả hoạt động trị liệu trong phục hồi chức năng sinh hoạt hàng ngày ở bệnh nhân nhồi máu não trên lều".

\section{II. ĐốI TƯợNG VÀ PHƯƠ'NG PHÁP NGHIÊN CỨU}

a) Đối tượng nghiên cứu. Là những bệnh nhân liệt nửa người do tai biến nhồi máu não vùng trền lều đã được khám, chẩn đoán xác định và điều trị tại Trung tâm phục hồi chức năng Bệnh viên Bạch Mai từ tháng 09/2020 đến tháng 03/2021.

Tiêu chuân lựa chơn bệnh nhân:

- Bệnh nhân liệt nửa người một bên do tai biến nhồi máu não trên lều, có 1 ổ nhồi máu đã được xác định trên $\mathrm{CT}$ hoăc $\mathrm{MRI}$

- Bệnh nhân bi đột quỵ não lần thứ nhất.

- Tuổi từ 45 đến 80.

- Thời gian mắc tai biến nhồi máu não máu não trong vòng ba tháng.

- Tình trạng nhận thức theo thang điểm MOCA > $=26$ điểm

- Bệnh nhân có điểm Barthel lúc vào viện <95 điểm

- Không có dấu hiệu màng não

- Đồng ý tham gia vào nghiên cứu.

Tiêu chuân loai trừ:

- Bệnh nhân không giao tiếp được.

- Bệnh nhân yếu tay bên liệt trước khi mắc đột quỵ não (bệnh cơ - xương - khớp, di chứng chấn thương...).

- Bệnh nhân bị tổn thương khớp vai trước đó (bệnh lý khớp vai, phần mềm quanh vai, chấn thương vai...)

- Bán trật khớp vai.

- Bệnh nhân tái phát đột quy não trong thời gian nghiên cứu.

Những bệnh nhân bị tử vong trong thời gian nghiên cứu bị loại khỏi nhóm nghiên cứu.

\section{b) Phương pháp nghiên cứu}

Phương pháp nghiên cứu: Tiến cứu có can thiệp, đánh giá trước và sau, không có nhóm chứng.

Địa điểm: Trung tâm Phục hồi chức năng, bệnh viện Bạch Mai.

Thời gian: 9/2020 - 7/2021.

Phương pháp lấy mẫu: lấy mẫu thuân tiện

Tiêu chuẩn đánh giá: Lượng giá chức năng sinh hoạt hàng ngày theo Barthel với các mức độ độc lập hoàn toàn, trợ giúp ít, trợ giúp trung bình và phu thuộc hoàn toàn.

Phương pháp đánh giá kết quả: So sánh tại 
thời điểm 1 tháng sau can thiệp với lúc nhập viện, tự đối chứng.

Xử lý số liệu: Số liệu được xử lý theo phần mềm SPSS16.0.

III. KẾT QUẢ NGHIÊN CỨU

Đăc điểm của đối tượng nghiên cứu

Bảng 3.1. Sự phân bố bệnh nhân theo nhóm tuổi nhóm tuổi

\begin{tabular}{|c|c|c|}
\hline Nhóm tuổi & $\begin{array}{c}\text { Số bệnh } \\
\text { nhẩn }\end{array}$ & Tỷ lệ \\
\hline $40-54$ & 5 & $16,7 \%$ \\
\hline $55-64$ & 8 & $26,7 \%$ \\
\hline $65-74$ & 11 & $36,7 \%$ \\
\hline$>=75$ & 6 & $20 \%$ \\
\hline Tống & $\mathbf{3 0}$ & $\mathbf{1 0 0} \%$ \\
\hline
\end{tabular}

Nhận xét: Nhóm tuổi chiếm tỉ lệ cao nhất là 65 - 74 tuổi, chiếm 36,7\% (tương đương 11 bệnh nhân), xếp thứ 2 và 3 lần lượt là nhóm tuổi 55 - 64 (chiếm 26,7\%) và nhóm tuổi $\geq 75$ (chiếm 20\%). Nhóm tuổi 40 - 54 chiếm 16,7\%. Không có bệnh nhân nào dưới 40 tuổi.

Mức độ độc lập trong sinh hoạt hàng ngày

Bảng 3.3 Điểm Barthel tại các thời điểm

\begin{tabular}{|c|c|c|c|}
\hline Chỉ số & Giá trị (điếm) & t & P \\
\hline Điếm trung bình chỉ số Barthel lúc vào viện & $29,17 \pm 8,62$ & & \multirow{2}{*}{$0,000<$} \\
\hline Điểm trung bình chỉ số Barthel sau 1 tháng & $62,83 \pm 13,18$ & \multirow{2}{*}{$-15,807$} & 0,01 \\
\hline Mức chênh lệch & 33,67 & & \\
\hline Điểm chỉ số Barthel nhỏ nhất & 20 & & \\
\hline Điểm chỉ số Barthel lớn nhất & 95 & & \\
\hline
\end{tabular}

Nhận xét: Trung bình điểm Barthel của bệnh nhân ở thời điểm vào viện là 29,17, sau khi điều trị 1 tháng là 62,83 , điểm Barthel trung bình tăng 33,67, sự cải thiện này có ý nghĩa thống kê $p<0,01$.

Bảng 3.4. Kêt quả mức độ độc lập trong sinh hoạt hàng ngày theo thời gian

\begin{tabular}{|c|c|c|c|c|c|c|c|c|}
\hline \multirow{2}{*}{$\begin{array}{l}\text { Mức độđộc lập } \\
\text { Thời gian }\end{array}$} & \multicolumn{2}{|c|}{$\begin{array}{l}\text { Độc lập } \\
\text { hoàn toàn }\end{array}$} & \multicolumn{2}{|c|}{ Trợ giúp ít } & \multicolumn{2}{|c|}{$\begin{array}{l}\text { Trợ giúp } \\
\text { trung bình }\end{array}$} & \multicolumn{2}{|c|}{$\begin{array}{l}\text { Phụ thuộc } \\
\text { hoàn toàn }\end{array}$} \\
\hline & $\mathbf{N}$ & Tỷ lệ & $\mathbf{n}$ & Tỷ lê & $\mathbf{n}$ & Tỷ lề & $\mathrm{n}$ & Tỷ lê \\
\hline Khi vào viện & 0 & $0 \%$ & 0 & $0 \%$ & 24 & $80 \%$ & 6 & $20 \%$ \\
\hline Sau 1 tháng & 1 & $3,3 \%$ & 18 & $60 \%$ & 11 & $36,7 \%$ & 0 & $0 \%$ \\
\hline
\end{tabular}

Nhận xét: Sau 1 tháng, 0 bệnh nhân phụ thuộc hoàn toàn, 36,7\% bệnh nhân cần trợ giúp trung bình ( $n=11), 60 \%$ bệnh nhân trợ giúp ít $(n=18)$ và $3,3 \%$ bệnh nhân độc lập hoàn toàn $(n=1)$.

Bảng 3.5. Sự cải thiện mức độ độc lập trong từng hoạt động sinh hoạt hàng ngày

\begin{tabular}{|c|c|c|c|c|c|}
\hline \multirow{2}{*}{ Hoạt động } & \multirow{2}{*}{ Mức độ độc lập } & \multicolumn{2}{|c|}{ Lúc vào viện } & \multicolumn{2}{|c|}{ Sau 1 tháng } \\
\hline & & $\mathrm{n}$ & Phần trăm & $\mathrm{n}$ & Phần trăm \\
\hline \multirow{3}{*}{ Ăn } & Không thể ăn & 5 & $16,7 \%$ & 1 & $3,3 \%$ \\
\hline & Cần trợ giúp & 18 & $60 \%$ & 8 & $26,7 \%$ \\
\hline & Độc lập & 7 & $23,3 \%$ & 21 & $70 \%$ \\
\hline \multirow{2}{*}{ Tắm } & Cần trợ giúp & 30 & $100 \%$ & 26 & $86,7 \%$ \\
\hline & Độc lập & 0 & $0 \%$ & 4 & $13,3 \%$ \\
\hline \multirow{2}{*}{$\begin{array}{l}\text { Vệ sinh đâu } \\
\text { mặt }\end{array}$} & Phụ thuộc & 27 & $90 \%$ & 4 & $13,3 \%$ \\
\hline & Độc lập & 3 & $10 \%$ & 26 & $86,7 \%$ \\
\hline \multirow{3}{*}{ Mặc quân áo } & Phụ thuộc & 28 & $93,3 \%$ & 0 & $0 \%$ \\
\hline & Cần trợ giúp & 2 & $6,7 \%$ & 26 & $86,7 \%$ \\
\hline & Độc lập & 0 & 0 & 4 & $13,3 \%$ \\
\hline \multirow{2}{*}{ Đại tiện } & Không tự chủ & 2 & $6,7 \%$ & 0 & $0 \%$ \\
\hline & Đôi lúc không tự chủ & 2 & $6,7 \%$ & 0 & $0 \%$ \\
\hline
\end{tabular}


VIETNAM MEDICAL JOURNAL N02 - SEPTEMBER - 2021

\begin{tabular}{|c|c|c|c|c|c|}
\hline & Tự chủ & 26 & $86,7 \%$ & 30 & $30 \%$ \\
\hline \multirow{3}{*}{ Tiểu tiện } & Không tự chủ & 1 & $3,3 \%$ & 1 & $3,3 \%$ \\
\hline & Đôi lúc không tự chủ & 1 & $3,3 \%$ & 0 & $0 \%$ \\
\hline & Tự chủ & 28 & $93,3 \%$ & 29 & $96,7 \%$ \\
\hline \multirow{3}{*}{$\begin{array}{l}\text { Sử dụng } \\
\text { TOILET }\end{array}$} & Phụ thuộc & 25 & $83,3 \%$ & 3 & $10 \%$ \\
\hline & Cân trợ giúp & 5 & $16,7 \%$ & 27 & $90 \%$ \\
\hline & Độc lập & 0 & $0 \%$ & 0 & $0 \%$ \\
\hline \multirow{4}{*}{ Dịch chuyển } & Không thế dịch chuyến $<50 \mathrm{~m}$ & 16 & $53,3 \%$ & 0 & $0 \%$ \\
\hline & Trợ giúp nhiều & 14 & $46,7 \%$ & 7 & $23,3 \%$ \\
\hline & Trợ giúp ít & 0 & $0 \%$ & 22 & $73,3 \%$ \\
\hline & Độc lập & 0 & $0 \%$ & 1 & $3,3 \%$ \\
\hline \multirow{4}{*}{ Di chuyển } & Không thế di chuyến $<50 \mathrm{~m}$ & 24 & $80 \%$ & 4 & $13,3 \%$ \\
\hline & Độc lập với xe lăn & 6 & $20 \%$ & 9 & $30 \%$ \\
\hline & Có trợ giúp & 0 & $0 \%$ & 15 & $59 \%$ \\
\hline & Độc lập & 0 & $0 \%$ & 2 & $6,7 \%$ \\
\hline \multirow{3}{*}{$\begin{array}{l}\text { Lên xuống } \\
\text { câu thang }\end{array}$} & Không thế được & 28 & $93,3 \%$ & 12 & $40 \%$ \\
\hline & Trợ giúp & 2 & $6,7 \%$ & 17 & $56,7 \%$ \\
\hline & Độc lập & 0 & $0 \%$ & 1 & $3,3 \%$ \\
\hline
\end{tabular}

Nhận xét: Mức độ độc lập hoạt động ăn, tắm, vệ sinh đầu mặt, mặc quần áo dịch chuyển, di chuyển, lên xuống câuu thang lúc vào viên lần lướt là $23,3 \%, 0 \%, 23,3 \%, 0 \%, 0 \%, 0 \%, 0 \%$ sau 1 tháng can thiệp tỳ lệ độc lập trong hoạt động trên lần lượt là $70 \%, 13,3 \%, 86,7 \%, 13,3 \%, 3,3 \%$, $6,7 \%, 3,3 \%$.

Bảng 3.6. Điểm trung bình các hoạt động hàng ngày ở các thời điểm

\begin{tabular}{|c|c|c|c|c|c|c|}
\hline \multirow{2}{*}{ Hoạt động } & \multicolumn{2}{|c|}{ Lúc vào viện } & \multicolumn{2}{c|}{ Sau 1 tháng } & t & p \\
\cline { 2 - 7 } & Trung bình & SD & Trung bình & SD & & \\
\hline Ān & 5,33 & 3,198 & 8,33 & 2,73 & $-5,835$ & $0,000<0,01$ \\
\hline Tắm & 0 & & 0,67 & 1,73 & $-2,112$ & $0,43>0,05$ \\
\hline Vệ sinh đâuu mặt & 0,5 & 1,526 & 4,33 & 1,73 & $-9,761$ & $0,000<0,01$ \\
\hline Mặc quần áo & 0,33 & 1,269 & 5,67 & 1,73 & $-16,000$ & $0,000<0,01$ \\
\hline Đại tiện & 9 & 2,754 & 10 & & $-1,989$ & $0,056>0,05$ \\
\hline Tiểu tiện & 9,5 & 2,013 & 9,67 & 1,83 & $-1,000$ & $0,326>0,05$ \\
\hline Sử dụng TỌLET & 0,83 & 1,9 & 4,5 & 1,53 & $-8,930$ & $0,000<0,01$ \\
\hline Dịch chuyến & 2,33 & 2,54 & 9 & 2,42 & $-13,359$ & $0,000<0,01$ \\
\hline Di chuyển & 1 & 2,034 & 7,5 & 4,1 & $-10,140$ & $0,000<0,01$ \\
\hline Lên xuống cầu thang & 0,33 & 1,269 & 3,17 & 2,78 & $-5,461$ & $0,000<0,01$ \\
\hline
\end{tabular}

Nhân xét: Sự cải thiên hoat động ăn, vê sinh đâu mặt, mặc quần áo, sử dụng Toilet, dịch chuyển, di chuyển, lên xuổng câu thang đều có ý nghĩa thống kê $p<0,01$.

\section{BÀN LUÂNN}

Nghiên cứu của chúng tôi thực hiện trên 30 đối tượng nhồi máu não trên lều tại Trung tâm PHCN, bệnh viện Bạch Mai đưa ra, sau 1 tháng can thiệp điểm Barthel trung bình tăng 33,67. Mức cải thiện này có ý nghĩa về mặt lâm sàng sàng cũng như về mặt thống kê bằng kiểm định ttest trước và sau can thiệp với $p=0,000(p<$ 0,01 ). Kết quả trên cũng tương đồng với tác giả Kamarul Imran và Thomas nghiên cứu sư thay đổi điểm Barthel Index trên 98 bệnh nhân đột quy não cấp tính ở Malaysia điểm Barthel lúc vào viện 35,1 , sau can thiệp 1 tháng 62,44 và sau 3 tháng 68,82 điểm [4]. Ở mức độ độc lập trong sinh hoạt hàng ngày, sau 1 tháng, 0 bệnh nhân phụ thuộc hoàn toàn, 36,7\% bệnh nhân cần trợ giúp trung bình $(n=11), 60 \%$ bệnh nhân trợ giúp ít ( $n=18)$ và $3,3 \%$ bệnh nhân độc lập hoàn toàn $(n=1)$. Phân bố và sự cải thiện này tương đồng với tác giả Lâm Thùy Mai và cộng sự ghi nhâan nhóm can thiệp gồm 30 bệnh nhân sau 1 tháng có $30 \%$ bệnh nhân trợ giúp trung bình, $66,7 \%$ trợ giúp ít và $3,3 \%$ độc lập hoàn toàn [1].

Tác giả Nguyễn Thị Kim Liên (2011) cho thấy chức năng sinh hoạt hàng ngày được cải thiện sau 1 tháng với độ tin cậy $>95 \%$, sau 3 và 6 tháng độ tin cậy >99\%[3]. Lê Huy Cường (2008) khi đánh giá kết quả $\mathrm{PHCN}$ vận động bàn tay bằng chỉ số Barthel sau 1 tháng mặc dù có cải thiện nhưng không có ý nghĩa thống kê $(p>0,05)$, sau 3 tháng hầu hết các hoạt động sinh hoạt hàng ngày đều cải thiên rõ $(p<0,05)$, tỷ lê người bênh độc lập trong sinh hoạt hàng ngày là 60\% [2]. 
Có sự khác biệt này giữa nghiên cứu của chúng tôi và một số nghiên cứu khác có thể là do nghiên cứu của chúng tôi có cõ̃ mẫu nhỏ nên tính đại diên chưa cao.

Sự cải thiện hoạt động ăn, vệ sinh đầu mặt, mặc quần áo, sử dụng Toilet, dịch chuyển, di chuyển, lên xuống cầu thang đều có ý nghĩa thống kê $p<0,01$. Có được sự cải thiện trên là dựa vào các chiến thuật của hoạt động trị liệu không những tạo thuận, tăng sức mạnh cơ cho bên liệt mà còn có các chiến thuật bù trừ. Cho người bệnh sử dụng dụng cụ thích nghi, định hướng vào các hoạt động chức năng để cải thiện khả năng độc lập trong các sinh hoạt cá nhân và dịch chuyển, di chuyển, lên xuống cầu thang.

\section{KẾT LUẦN}

Sau can thiệp 1 tháng, điểm Barthel trung bình tăng 33,67 , có $36,7 \%$ bệnh nhân cần trợ giúp trung bình, $60 \%$ bệnh nhân trợ giúp ít và 3,3\% bệnh nhân độc lập hoàn toàn, 0 bệnh nhân phụ thuộc hoàn toàn.

\section{TÀI LIẸU THAM KHẢO}

1. Lâm Thùy Mai (2019), "Đánh giá hiệu quả phục hồi chức năng chi trên ở bênh nhân liệt nứa người do nhồi máu não", Tạp chí Ý học Việt Nam, 8.

2. Lê Huy Cường (2008), "Đánh giá kết quả hoạt động trị liệu trong phục hồi chức năng vận động chi trên ở bệnh nhân tai biến chảy máu não trên lều", Luâan vằn tốt nghiệp thạc sỹ Y khoa, trường Đại học Y Hà Nội.

3. Nguyễn Thị Kim Liên (2011), " Nghiên cứu PHCN bàn tay trên bênh nhân liêt nửa người do tai biến mạch máu não", Luận án tiến sĩ Y học, Trường Điai học Y Hà Nối.

4. Kamarul Imran, Thomas J. Keegan (2020), "The change of Barthel Index scores from thetime of discharge until 3-month postdischargeamong acute stroke patients inMalaysia: A random intercept model", PMCID: PMC6301695.

5. Smith J.C.F., Walker M.F., Sunderland A., at el. (2010), An interrater reliability study of the Nottingham stroke Dressing Assessment, British Journal of Occupational Therapy, $1-2$.

6. Adams R.D, Victor.M (1993), "Discases of the spinal cord, Principles of neurology", New York 1078 - 1116.

\section{TỔNG QUAN VỀ HIỆU QUẢ ĐÓNG CHÓP RĂNG VĨNH VIỄN BẰNG MINERAL TRIOXYDE AGGREGATE}

\section{TÓM TẮT. \\ Mục tiêu: Tổng kết hiệu quả điều trị đóng chóp răng vĩnh viê̂n bằng Mineral Trioxyde Aggregate (MTA) theo phương pháp tổng quan có hệ thống. Phương pháp: Tổng quan nghiên cứu có hể thống với nhóm can thiệp sử dụng MTA, nhóm đối chứng sử dụng calcium hydroxide $\left(\mathrm{Ca}(\mathrm{OH})_{2}\right)$. Trên đối tượng có rằng vĩnh viễn chưa đóng chóp vì bệnh lý tủy hoại tử hoặc viêm quanh chóp mạn tính. Kểt quả: Thời gian đóng chóp trung bình của nhóm chứng dao động trong khoảng từ $1,35 \pm 0,275$ tháng đến 3,0 $\pm 2,9$ tháng, trong khi thời gian đóng chóp của nhóm đối chứng dao động từ 1,95 $\pm 0,45$ tháng đến 7,93 $\pm 2,53$ tháng. Số răng hình thành hàng rào tố chức cứng quanh chóp ở nhóm chứng từ 7 - 29 răng, ở nhóm đối chứng từ 9 - 27 răng. Tỷ lệ đóng chóp thành công trên lâm sàng của các răng ở nhóm MTA dao động trong khoảng từ $90 \%$ đến $100 \%$. Tỷ lệ đóng chóp thành công trên lâm sàng của các răng ở các nhóm}

${ }^{1}$ Viện Đào tạo Răng Hàm Mặt, Trường Đại học Y Hà Nội ${ }^{2}$ Bệnh viện Dệt May Hà Nội

Chịu trách nhiệm chính: Đỗ Thị Thanh Tâm

Email: Bacsynhakhoathanhtam@gmail.com

Ngày nhận bài: 21.6.2021

Ngày phản biện khoa học: 20.8.2021

Ngày duyệt bài: 26.8.2021

\section{Đỗ Thị Thanh Tâm ${ }^{1}$, Trịnh Thị Thái Hà ${ }^{1}$ Lê Hồng Vân' ${ }^{1}$ Cao Thị Nhung ${ }^{2}$}

đối chứng dao động trong khoảng từ 73,30\% đến 93,33\%. Tỷ lệ đóng chóp thành công trên X-quang của các răng ở nhóm MTA dao động trong khoảng từ $82,4 \%$ đến $100 \%$. Tỷ lệ đóng chóp thành công trên Xquang của các răng ở các nhóm đối chứng dao động trong khoảng từ 75\% đến 93,33\%. Kết luận: Cả hai vât liệu $\mathrm{MTA}$ và $\mathrm{Ca}(\mathrm{OH})_{2}$ đều có tỷ lệ đóng chóp thành cổng trên lâm sàng, tỷ lệ thành công trên X-quang tương tự nhau. Tuy nhiên, về thời gian hình thành hàng rào tổ chức cứng (HRTCC) quanh chóp ở nghiên cứu này của MTA ngắn hơn rõ rệt so với $\mathrm{Ca}(\mathrm{OH})_{2}$.

Tư khóa: Răng vĩnh viễn chưa đóng chóp, MTA, Apexification

\section{SUMMARY \\ APEXIFICATION OF IMMATURE PERMANENT TEETH WITH MINERAL TRIOXYDE AGGREGATE: SYSTEMATIC REVIEW}

Objectives: The aim of this study was to conduct a quantitative systematic review, including published data, comparing the efficacy of mineral trioxide aggregate as material used for the endodontic management of immature teeth. Methods: A systematic review of the intervention group using MTA, the control group using calcium hydroxide $\left(\mathrm{Ca}(\mathrm{OH})_{2}\right)$. In subjects with imature permanent teeth because of necrotizing pulp disease or chronic apical periodontitis. Results: The time required for apical 